\title{
The Expression of Can and Camk is Associated with Lipogenesis in the Muscle of Chicken
}

http://dx.doi.org/10.1590/1516-635x1703287-292

\section{-Author(s)}

Yang $Y$

Song $J^{\prime}$

Fu R"

Sun $Y^{\prime \prime}$

Wen J"

College of Animal Science, Yangtze University, Jingzhou, Hubei 434025, P. R. China;

" State Key Laboratory of Animal Nutrition, Institute of Animal Sciences, Chinese Academy of Agricultural Sciences, Beijing 100094, P. R. China

\section{Mail Address}

Corresponding author e-mail address Dr. Ye Yang

College of Animal Science, Yangtze University, 1 Nanhuan Road, Jingzhou, Hubei, Zip code: 434025, China E-mail: yangyecaas@sina.com

\section{nKeywords}

Ca2+/calmodulin-dependent protein kinase; calcineurin; chicken; regulation.

\section{ABSTRACT}

Intramuscular fat (IMF) content in chickens significantly contributes to meat quality. The main objective of this study was to assess the expression of calcineurin $(\mathrm{CaN})$ and $\mathrm{Ca}^{2+} /$ calmodulin-dependent protein kinase (CaMK) in lipogenesis in chicken muscle. Chickens were slaughtered and sampled at 4, 8, and 16 weeks of age. IMF content and the expression of CaN subunits and CaMK isoforms were measured in the thigh muscle tissue. The results showed that the IMF contents were greater at 16 weeks compared with those at 4 and 8 weeks $(p<0.05)$. Transcription of fatty acid synthase (FAS) and fatty acid translocase CD36 (FAT/CD36) mRNA significantly increased with age, from four to 16 weeks $(p<0.05)$. The mRNA levels of CaN B and CaMK IV were significantly lower at 16 weeks than at four weeks $(p<0.05)$, but CaMK II mRNA levels were significantly higher than at four weeks $(p<0.05)$. In order to evaluate the role of CaMK and CaN in adipogenesis, SV cells were incubated in standard adipogenic medium for $24 \mathrm{~h}$ and treated with specific inhibitor of CaMK and CaN. The expressions of CCAAT/ enhancer binding protein $\beta$ (C/EBP $\beta$ ), sterol regulatory element-binding protein 1 (SREBP1), and peroxisome proliferation-activated receptor $\gamma$ (PPARy) were dramatically enhanced by the CsA, CaN inhibitor $(\mathrm{p}<0.05)$. KN93, CaMK II inhibitor, dramatically repressed the expression of those lipogenic gene $(p<0.05)$. These results indicated that $\mathrm{CaN}$ and CaMK had different effects on adipogenesis in the muscle of chickens.

\section{INTRODUCTION}

It is generally accepted that intramuscular fat (IMF) content is an important indicator of meat quality (Zhao et al., 2007; Choi \& Kim, 2009; Hocquette et al., 2010). The problems of meat quality, such as sensory characteristics, tenderness and physical attributes, are related to fat accumulation in broilers. Adipogenesis is a well-regulated process regulated by many important transcription factors, such as CCAAT/ enhancer-binding protein factors $(C / E B P \alpha, C / E B P \beta)$, sterol regulatory element-binding protein 1 (SREBP1), and peroxisome proliferatoractivated receptors (PPAR $\alpha$ and PPAR $\gamma$ ). PPARy is the main regulator of adipogenesis (Peter \& Bruce, 2008). SREBP1 and C/EBPB, expressed in the early stages of adipogenesis, induce the expression of $P P A R \gamma$ at later stages of cell differentiation. Activation of PPAR plays a crucial role in the expression of adipocyte gene, such as fatty acid synthase (FAS) and fatty acid translocase CD36 (FAT/CD36) (Lin et al., 2011).

Adipogenesis is also regulated by calcium signaling pathways (Shi et al., 2000). The mechanism of increased $\mathrm{Ca}^{2+}$ levels repressing lipogenesis maybe contribute to the calmodulin ( $\mathrm{CaM}$ ) kinase cascade, which can activate both $\mathrm{Ca}^{2+} / \mathrm{CaM}$-dependent protein kinase (CaMK) and $\mathrm{Ca}^{2+} / \mathrm{calmodulin}(\mathrm{CaM})$-dependent phosphatase, calcineurin ( $\left.\mathrm{CaN}\right)$ 
(MacDonnell et al., 2009). Lin et al. (2011) showed that the $\mathrm{Ca}^{2+} / \mathrm{calmodulin}$-dependent protein kinase kinase 2 (CaMKK2), activated by the CaM, inhibits pre-adipocyte differentiation. CaMK $N$, which is a downstream kinase, can be phosphorylated by CaMKK2. Many studies demonstrated CaN is involved in the regulation of adipocyte differentiation by preventing the expression of transcription factors of adipocyte differentiation (Neal \& Clipstone, 2002). In addition, lipid mediators, such as prostaglandins 2 and IL-15, directly inhibit adipocyte differentiation via calcineurin-dependent mechanism that acts preventing the expression of the critical transcription factors PPARy and C/EBPa (Liu \& Clipstone, 2007; Almendro et al., 2009).

To date, CaN and CaMK functions in lipogenesis have been described by the adipocyte model. There is still little information on the role of $\mathrm{CaN}$ and CaMK in the lipogenesis in the chicken muscle. The objective of the present study was to analyze the association between the expression of CaN and CaMK and lipogenesis in the chicken skeletal muscle.

\section{MATERIALS AND METHODS}

\section{Use of birds}

All animal procedures and care were performed in accordance with the Guidelines for Experimental Animals established by the Ministry of Science and Technology (Beijing, China).

Ninety one-d-old female Bei Jing You (BJY) chickens (Institute of Animal Sciences, Chinese Academy of Agricultural Sciences, Beijing, China) were raised starting from day 1 . The starter feed (1-21 days) contained $20 \%$ crude protein and $12.01 \mathrm{MJ} / \mathrm{kg}$, and the grower feed ( $>22$ days) contained $19 \%$ crude protein and $12.55 \mathrm{MJ} / \mathrm{kg}$. Feed and water were provided ad libitum during the experiment. Twelve birds were sacrificed per week at 4, 8, and 16 weeks of age, and the thigh muscles were collected. The right thigh muscles collected from the 12 birds sacrificed each week were stored at $-20^{\circ} \mathrm{C}$ to determine intramuscular fat (IMF) content by ether extraction in a Soxhlet apparatus (Zhao et al., 2007), which was expressed as a the percentage of muscle weight (on dry matter basis). The left thigh muscles collected from the same birds were stored at $-80^{\circ} \mathrm{C}$ for RNA extraction.

\section{Cell isolation and culture}

All reagents for cell culture were acquired from Sigma-Aldrich (St. Louis, MO), unless noted otherwise.
The birds were sacrificed by $\mathrm{CO}_{2}$ asphyxia. The pectoral muscle (PM) was isolated aseptically and finely minced after removing all visible connective tissue. The muscle stromal-vascular (SV) cells were obtained according to the procedure modified from a previous report (Hausman \& Poulos, 2005).

Pectoral muscle tissue was digested for 30-40min by $0.1 \%$ collagenase type I (GIBCO, Grand Island, NY, USA) and then centrifuged at $1000 \times \mathrm{g}$ for $8 \mathrm{~min}$, after which the cell pellets were digested for 15-20min by $0.25 \%$ trypsin (GIBCO, Grand Island, NY, USA). The digesta were filtered through 200, 400 and 600 mesh screens to aseptically isolate the digested cells, which were subsequently centrifuged at $1000 \times \mathrm{g}$ for $5 \mathrm{~min}$. Cells were rinsed with Dulbeco's modified Eagle's medium with F12 (DMEM/F12, 1:1,GIBCO,Grand Island, NY, USA), centrifuged at $1000 \times \mathrm{g}$ for $5 \mathrm{~min}$, and re-suspended in $15 \mathrm{~mL}$ growth media containing $84 \%$ DMEM/F12, 15\% fetal bovine serum (FBS, GIBCO, Grand Island, NY, USA), 1\% HEPES, and penicillin 100U/ $\mathrm{mL}$, streptomycin $100 \mathrm{U} / \mathrm{mL}$. Cells were then plated on 6 -well culture plates at $37^{\circ} \mathrm{C}$ in humidified $(5 \%) \mathrm{CO}_{2}$ atmosphere. The cell cultures were aspirated from the plate $1 \mathrm{~h}$ after plating and fresh growth medium was added to each plate, as described by Hausman \& Poulos (2005).

At $30 \%$ confluence, SV cells were incubated in adipogenic medium composed of $10 \%$ FBS /DMEM supplemented with insulin $(10 \mu \mathrm{g} / \mathrm{mL})$, dexamethasone (1 $\mu \mathrm{M})$, 3-isobutyl-1-methylxanthine (IBMX, 115ng/ $\mathrm{mL}$ ). In order to determine the role of CaMK and CaN on adipogenesis regulation, SV cells were cultured for $24 \mathrm{~h}$ in the presence of CaMK inhibitor KN93 (KN93, $5 \mu \mathrm{mol} / \mathrm{L}$ ) or CaN inhibitor cyclosporin A (CsA, 500ng/ $\mathrm{mL}$ ), respectively, or in the absence of these inhibitors as a control treatment (CON). The cells were collected at $24 \mathrm{~h}$ after initiating incubation for RNA extraction and mRNA analyses.

\section{Real-Time Quantitative PCR}

Total RNA was extracted using Trizol reagent (Invitrogen, USA), according to the manufacturer's instructions. After DNase I (Promega, Beijing, China) treatment, total RNA concentrations were measured by spectrophotometry (optical density of $260 \mathrm{~nm}$ and $280 \mathrm{~nm}$ ). All purified total RNA samples were diluted to $1 \mu \mathrm{g} / \mu \mathrm{L}$ in RNase-free water and stored at $-80^{\circ} \mathrm{C}$ for quantitative reverse transcription-polymerase chain reaction (PCR) assays.

Reverse transcription of $2 \mu \mathrm{g}$ RNA to first-strand cDNA was performed using a kit, according to the 
manufacturer's instruction (Promega, Beijing, China). Specific mRNAs were quantified by qPCR with an $A B I$ 7500 Real-time Detection System (Applied Biosystems, USA) using a SYBR ${ }^{\circledR}$ Premix Ex Taq ${ }^{\mathrm{TM}}$ \| kit (Takara, Dalian, China). The primers (Beijing Genome Institute, Beijing, China), based on chicken sequences, are listed in Table 1. Gene specific primers were designed by Primer Premier 5.0 from the corresponding chicken sequence to be intron spanning in order to avoid coamplification of genomic DNA. $\beta$-actin was used as candidate housekeeping genes. The amplification was performed in a total volume of $20 \mu \mathrm{L}$, containing 10 $\mu \mathrm{L} 2 \times$ SYBR Green I real-time PCR Master Mix(ABI), 1 $\mu \mathrm{L}$ forward primer $(10 \mathrm{pmol}), 1 \mu \mathrm{L}$ reverse primer (10 pmol), $2 \mu \mathrm{L}$ cDNA, $0.4 \mu \mathrm{L} 50 \times$ ROX Reference Dye II, and $5.6 \mu \mathrm{L} \mathrm{dH} 2 \mathrm{O}$. The real-time PCR program started with denaturation at $95^{\circ} \mathrm{C}$ for $1 \mathrm{~min}$, followed by 40 cycles of $95^{\circ} \mathrm{C}$ for $15 \mathrm{~s}$ and $60^{\circ} \mathrm{C}$ for $60 \mathrm{~s}$. Dissociation analysis of the amplification products was performed after each PCR to confirm that only one PCR product was amplified and detected.

Data were analyzed using the ABI 7500 SDS software $(A B I)$, with the baseline set automatically by the software, and average dCT values (normalized using $\beta$-actin) were exported into Excel spreadsheets to calculate relative mRNA expression. The $2^{-\Delta \Delta c t}$ method of quantification was used to calculate the relative gene expression levels (Livak \& Schmittgen, 2001).

\section{Statistical analysis}

All data were submitted to the analysis of variance (ANOVA) procedure of SAS (version 8.0). Differences between the means were evaluated using Duncan's multiple range test.

\section{RESULTS AND DISCUSSION}

\section{The accumulation of IMF and expression of the lipogenic gene in the thigh muscle}

The IMF contents increased with broiler age, particularly from 8 to 16 weeks ( $p<0.05$, Fig. 1), consistent with FAS, FAT/CD36 gene expression (Fig. 2).

FAT/CD36 is a membrane receptor that facilitates long-chain fatty acid uptake. In avian species, the liver, and not the adipose tissue, is the main site of de novo FA synthesis. Therefore, the free fatty acid storage in the muscle mainly depends on membrane protein transportation systems, such as FAT/CD36 (Holloway et al., 2008). The metabolic activity of adipocytes inside the muscle tissue also effects lipid deposition in the muscle (Rollin et al., 2003), and therefore, many key lipogenic genes have been postulated as good markers for IMF content, such as FAS. The FAS and FAT/CD36 genes play essential roles in adipogenesis, and high muscle lipid content is accompanied by a greater abundance of the FAT/CD36 and FAS (Li et al., 2011), which is consistent with our results.

Table 1 - Gene accession numbers and primer sequences ${ }^{1}$

\begin{tabular}{|c|c|c|c|}
\hline Genes2 & Primer sequence & Product, bp & Accession number \\
\hline FAT/CD36 & $\begin{array}{l}\text { F: 5'-TAATCATCGCAGGTTCT-3' } \\
\text { R: 5'-GCTTATTTGGGTTATTCAGT-3' }\end{array}$ & 104 & DQ323177.1 \\
\hline FAS & $\begin{array}{l}\text { F: 5'-CAATGGACTTCATGCCTCGGT-3' } \\
\text { R: 5'-GCTGGGTACTGGAAGACAAACA-3' }\end{array}$ & 126 & $J 04485$ \\
\hline PPAR $\gamma$ & $\begin{array}{l}\text { F: 5'AGTCCTTCCCGCTGACCAAA 3' } \\
\text { R: 5'TCTCCTGCACTGCCTCCACA 3' }\end{array}$ & 168 & AF470456.1 \\
\hline CIEBP $\beta$ & $\begin{array}{l}\text { F:5' GCCCGACTACACCTACATCAGC 3' } \\
\text { R:5' GCTCCACTTGGTCTCCACGAT 3' }\end{array}$ & 185 & NM_205253 \\
\hline SREBP1 & $\begin{array}{l}\text { F: 5' AAGGGCATTGACCTAAGCA 3' } \\
\text { R: 5' GGAGAAGCCAGCCTGTGA 3' }\end{array}$ & 135 & AJ414379.1 \\
\hline $\mathrm{CaN} \alpha$ & $\begin{array}{l}\text { F: 5'-TTCAACTGCTCCCCTCAT-3' } \\
\text { R: 5'-AACCATCTTCTTCTGTCCCT-3' }\end{array}$ & 151 & AY324834.1 \\
\hline $\operatorname{CaN} \beta$ & $\begin{array}{l}\text { F: 5'-TGGAGGACGACAGACCC-3' } \\
\text { R: 5'-CAGGCAAGACATAAGTGAGTAA-3' }\end{array}$ & 245 & NM_001030340.1 \\
\hline CAMK II & $\begin{array}{l}\text { F: 5'-CCAAGGGGAACAACAGGC-3' } \\
\text { R: 5'-CTTCAAGCAATCTACCGTCT-3' }\end{array}$ & 385 & AJ720104.1 \\
\hline CAMK IV & $\begin{array}{l}\text { F: 5'-GCAGGCAGAAAGGGAC-3' } \\
\text { R: 5'-GTGAAAGGCGAAGAAGG-3' }\end{array}$ & 105 & NM_001034813 \\
\hline$\beta$-actin & $\begin{array}{l}\text { F: 5'-GCGGCTTTGGTGACTCTA-3' } \\
\text { R: 5'-CTGCCTTCCTTGGATGTG-3' }\end{array}$ & 194 & AF173612 \\
\hline
\end{tabular}

'All primers were designed from chicken sequences using the software Primer Premier 5.0

${ }^{2} F A T / C D 36=$ fatty acid transporter $C d 36 ; F A S=$ fatty acid synthase; PPAR $\gamma=$ peroxisome proliferator-activated receptor $\gamma ; C / E B P=C C A A T /$ enhancer binding protein; SREBP $=$ sterol regulatory element-binding protein; $C a N=$ calcineurin; $C A M K=\mathrm{Ca}^{2+} /$ calmodulin-dependent protein kinase. 
Figure 1 - The IMF deposition in the muscle of chickens at different ages.

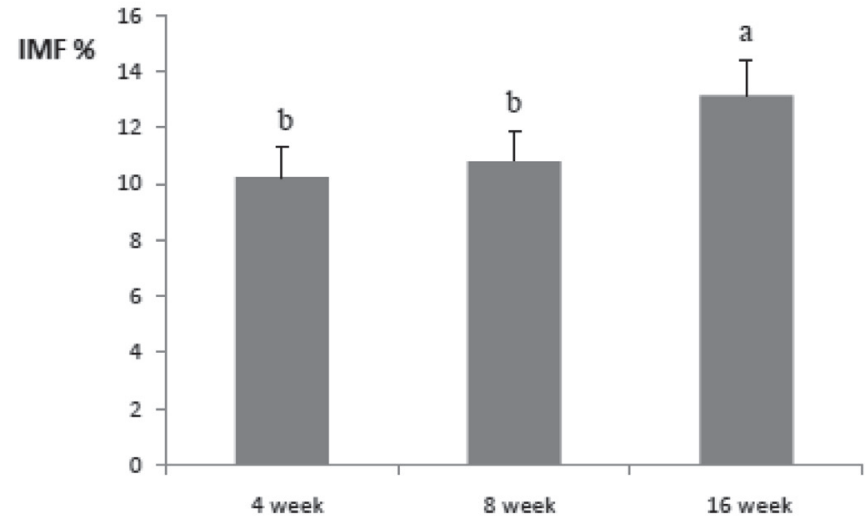

(a,b) Different letters indicate significant differences among ages $(p<0.05)$. Values are shown as mean \pm standard deviation. IMF expressed as percentage based on thigh muscle tissue on dry matter basis.

Figure 2 - Relative mRNA expression levels of lipogenic genes in chickens of different ages.

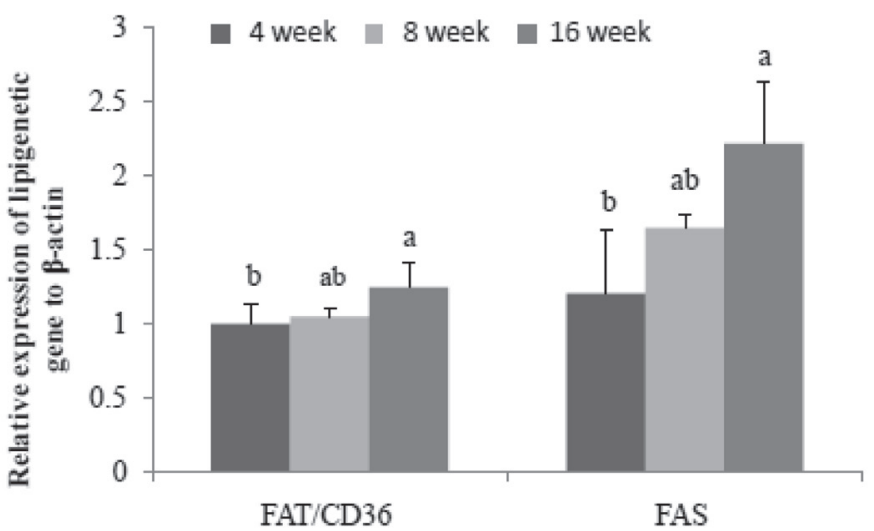

(a,b) Different letters indicate significant differences among ages $(p<0.05)$ for the same gene. Values are expressed as mean \pm standard deviation.

\section{The expression of $\mathrm{CaN}$ and CaMK in the thigh muscle}

The results obtained for mRNA levels of CaN subunits and CaMK isoforms in the thigh muscle are presented in Figure 3. The CaNA expression in the thigh muscle was not significantly influenced by bird age. CaNB and CaMK IV mRNA levels at 16 weeks were significantly lower than those at 4 weeks, but CaMK II mRNA levels were significantly higher at 16 weeks relative to 4 weeks $(p<0.05)$.

In order to examine the role of CaMK and CaN in adipogenesis regulation, SV cells were cultured in an adipogenic medium and treated with KN93 and CsA, which is the specific inhibitor of CaMK I/ and CaN. The results showed that KN93 and CsA had opposite effects on the expression of lipogenic gene. Compared with the control, CsA (CaN inhibitor) dramatically increased
Figure 3 - Relative mRNA expression levels of $\mathrm{CaN}$ and CaMK subunits in chickens of different ages.

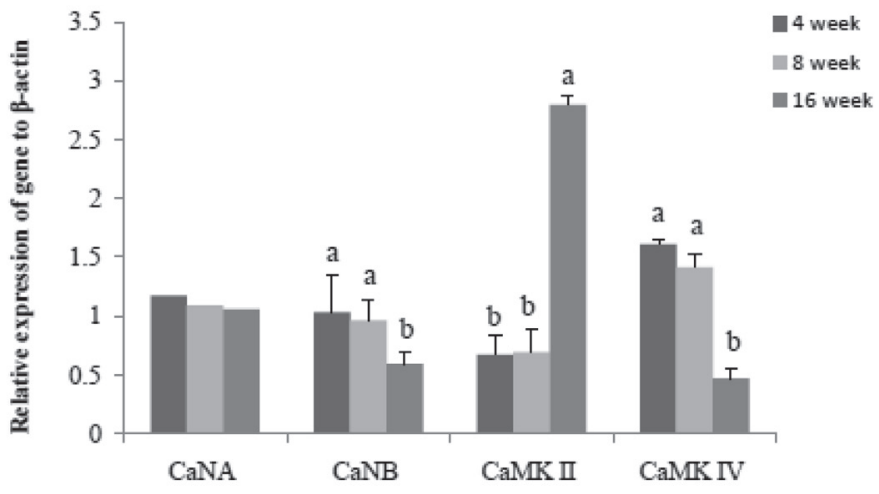

${ }^{(a, b)}$ Different letters indicate significant differences among ages $(p<0.05)$ for the same gene. Values are expressed as mean \pm standard deviation.

the expression of C/EBPB, SREBP1 and PPAR ; however, KN93 (CaMK II inhibitor) significantly repressed the expression of those lipogenic genes $(p<0.05$, Fig. 4).

Figure 4 - The effect of $\mathrm{CaN}$ and CaMK inhibitor on the adipogenic gene expression.

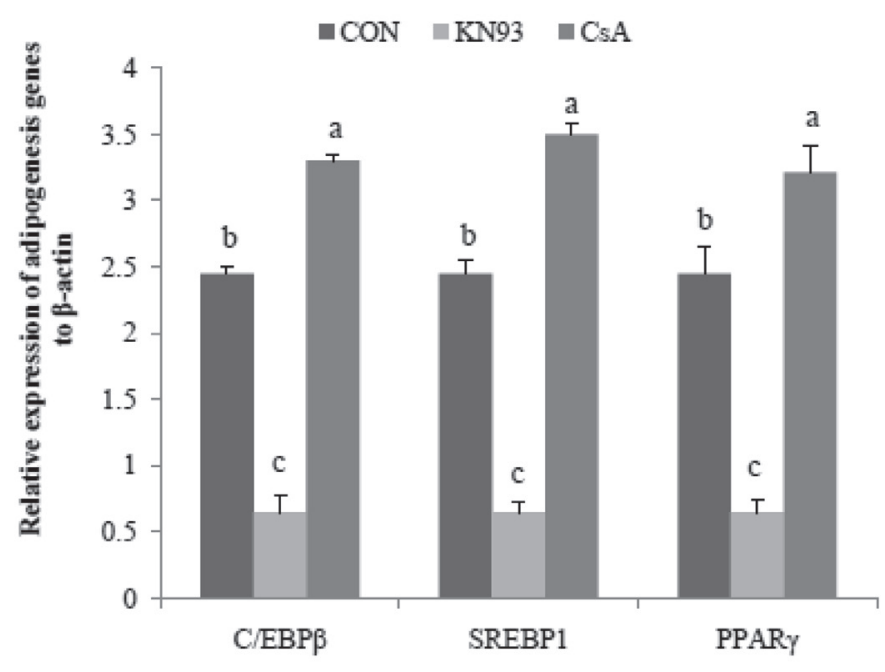

$(a, b, c)$ Different letters indicate significant differences $(p<0.05)$ in the expression of a same gene. Values are expressed as mean \pm standard deviation.

CaN and CaMK are believed to be associated with muscle lipid metabolism (Long \& Zierath, 2008). Adipogenesis is regulated by CaM kinase signaling pathways (Lin et al., 2011). The high level of intracellular $\mathrm{Ca}^{2+}$ in preadipocytes can inhibit adipogenesis, which may be due to the CaM kinase cascade. As downstream kinases, CaN and CaMK IV can be activated by CaM kinase. CaN and CaMK IV acts as a $\mathrm{Ca}^{2+}$-dependent molecular switch that negatively regulates the ability of 3T3-L1 cells to undergo adipocyte differentiation by preventing the expression of critical adipogenic transcription factors, such as C/ EBP $\beta / \delta$, SREBP1 and PPAR (MacDonnell et al., 2009; 
Lin et al., 2011). In present study, the role of CaMK II was different than those of CaMK IV and CaN in the expression of lipogenic gene. The SV cell, incubated with CSA and KN93, exhibited a different expression of lipogenic genes. CSA increased the expression of C/ $E B P \beta, S R E B P 1$ and PPARy, whereas KN93 had opposite effects. Although as $\mathrm{Ca}^{2+}$-dependent enzymes $\mathrm{CaN}$ and CaMK II play a different role in lipogenesis, CaMK II appears to provide a $\mathrm{Ca}^{2+}$-independent pathway for stimulating adipogenesis (Meldolesi, 2008). CaMK II can inhibit CaN via the inhibition of NFAT nuclear translocation, which results in the activation of PPAR and CIEBP $\alpha$ (MacDonnell et al., 2009). However, further research on the signal pathway of CaMK II in lipogenesis needs to be carried out.

\section{CONCLUSION}

Different expression of CaN and CaMK during the IMF deposition in chicken thigh muscle were demonstrated. The results of the present study indicate that transcription of CaN and CaMK was significantly correlated with lipogenesis in chickens thigh muscle.

\section{ACKNOWLEDGEMENTS}

The study was supported by the Natural Science Foundation of Hubei Province of China (2011CDB012) and Project of State Key Laboratory of Animal Nutrition (2004DA125184F1012). The authors would like to thank Enago (www.enago.cn) for the English language review.

\section{REFERENCES}

Almendro V, Fuster G, Ametller E, Costelli P, Pilla F, Busquets S, Figueras M, Argiles JM, Lopez-Soriano JF. Interleukin-15 increases calcineurin expression in 3T3-L1 cells: Possible involvement on in vivo adipocyte differentiation. International journal of molecular medicine 2009;24:453-458.

Choi YM, Kim BC. Muscle fiber characteristics, myofibrillar protein isoforms, and meat quality. Livestock Science 2009;122:105-118.

Hausman GJ, Poulos SPA. Method to establish co-cultures of myotubes and preadipocytes from collagenase digested neonatal pig semitendinosus muscles. Journal of Animal Science 2005;83:1010-1016.

Hocquette JF, Gondret F, Baéza E, Médale F, Jurie C, Pethick DW. Intramuscular fat content in meat-producing animals: development, genetic and nutritional control, and identification of putative markers. Animal 2010;4:303-319.

Holloway GP, Luiken J, Glatz JFC, Spriet LL, Bonen A. Contribution of FAT/ CD36 to the regulation of skeletal muscle fatty acid oxidation: an overview. Acta Physiologica 2008;194:293-309.

Li MH, Paran C, Wolins NE, Horowitz JF. High muscle lipid content in obesity is not due to enhanced activation of key triglyceride esterification enzymes or the suppression of lipolytic proteins. American Journal of Physiology. Endocrinology and Metabolism 2011;300:E699-E707.

Lin FM, Thomas JR, Anthony RM. The Ca+2+/Calmodulin-Dependent Protein Kinase Kinase, CaMKK2, Inhibits Preadipocyte Differentiation. Endocrinology 2011;152:3668-3679.

Liu L, Clipstone NA. Prostaglandin F2 alpha inhibits adipocyte differentiation via a G alpha q-calcium-calcineurin-dependent signaling pathway. Journal of Cellular Biochemistry 2007;100(1):161-73.

Livak KJ, Schmittgen TD. Analysis of relative gene expression data using realtime quantitative PCR and the $2^{-\Delta \Delta \mathrm{ct}}$ method. Methods 2001;25:402408 .

Long YC, Zierath JR. Influence of AMP-activated protein kinase and calcineurin on metabolic networks in skeletal muscle. American Journal of Physiology. Endocrinology and Metabolism 2008;295:E545-E552.

MacDonnell SM, Weisser-Thomas J, Kubo H, Hanscome M, Liu QH, Jaleel N, Berretta R, Chen XW, Brown JH, Sabri AK, Molkentin JD, Houser SR. CaMKII negatively regulates calcineurin-NFAT signaling in cardiac myocytes. Circulation Research 2009;105:316-325.

Meldolesi J. Inhibition of adipogenesis: a new job for the ER $\mathrm{Ca}^{2+}$ pool. The Journal of Cell Biology 2008;182(1):11-13

Neal JW, Clipstone NA. Calcineurin mediates the calciumdependent inhibition of adipocyte differentiation in 3T3-L1 cells. Journal of Cellular Biochemistry 2002;277:49776-49781.

Peter T, Bruce MS. Fat and beyond: the diverse biology of PPARgamma Annual Review of Biochemistry 2008;77:289-312.

Rollin X, Mé dale F, Gutières S, Blanc D, Kaushik SJ. Short and long term nutritional modulation of Acetyl-Coenzyme A Carboxylase activity in selected tissues of Rainbow Trout (Oncorhynchus mykiss). British Journal of Nutrition 2003;89:803-810.

Shi $\mathrm{H}$, Halvorsen YD, Ellis PN, Wilkison WO, Zemel MB. Role of intracellular calcium in human adipocyte differentiation. Physiological Genomics 2000:3:75-82

Zhao GP, Wen J, Chen JL, Zheng MQ, Zhang Y. Correlated responses to selection for increased intramuscular fat in a Chinese quality chicken line. Poultry Science 2007;86:2309-2314. 


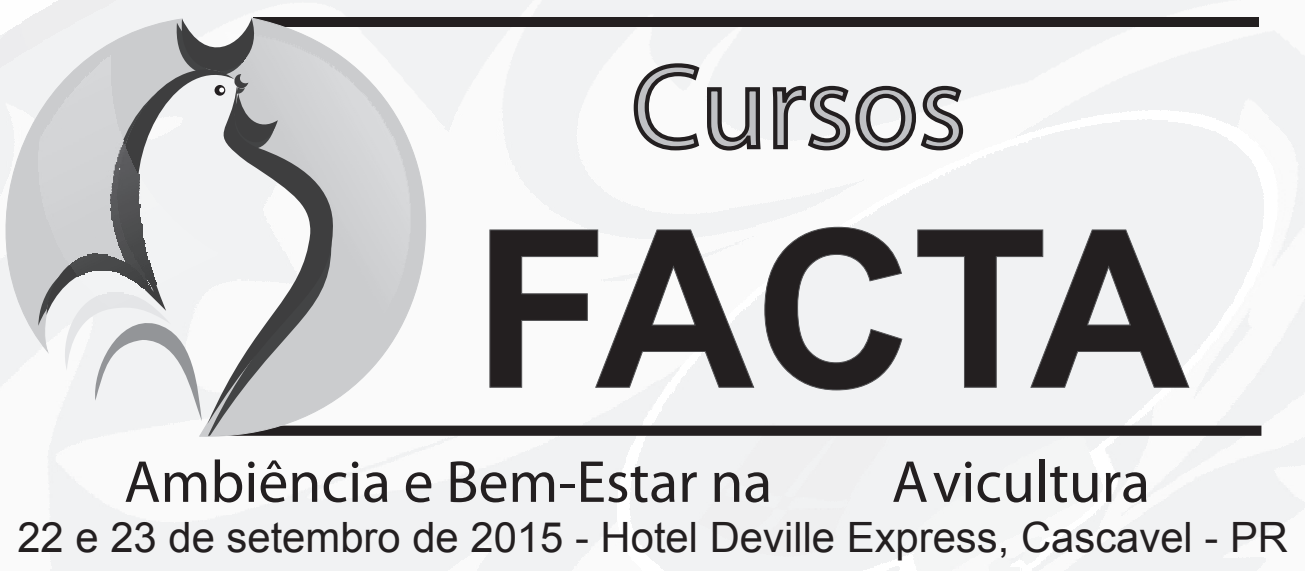

Confira a programação e increva-se!

Parcelamento em 3x no cartão de crédito

www.facta.org.br/cursoambiencia

Patrocinadores

AKSO

E PLASSON ${ }^{\circ}$

Produtos Eletrônicos

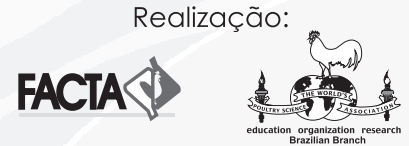

